\title{
Presentación
}

\section{Las exigencias de una nueva etapa}

La revista Realidad aparece como sucesora de nuestro Boletín de Ciencias Económicas y Sociales, creado en 1978 por los departamentos de Economía, Sociología y Ciencias Políticas. Pasar de un boletín a una revista quiere marcar un cambio cuantitativo y cualitativo en la investigación y en la proyección social de nuestros departamentos. No sólo es cuestión de nuevo formato y mayor número de páginas, sino de un enfoque actualizado de acuerdo a las exigencias de nuestra "realidad" nacional y regional. Desde 1978 siempre fue nuestra preocupación el análisis de la realidad económica y social, "dando así vigencia, en alguna forma, al postulado de proyección social de la Universidad" (Boletín № 1, mayo-1978).

Durante el primer quinquenio (1978-1982) el Boletín ofrecia más bien análisis y respuestas breves y ágiles sobre temas coyunturales, aunque en nuestras realidades económicas lo coyuntural va hermanado con lo estructural. Al iniciar el segundo quinquenio, el Editorial de enero-1983 llevaba por título: "Hacia una Nueva Etapa". EI cambio de formato y mayor densidad de los artículos quería reflejar la profundización de la crisis estructural: "Los problemas económicos, sociales y políticos de los países centroamericanos y la guerra civil que azota a El Salvador presentan grandes y apremiantes desafios a las instituciones dedicadas al quehacer o a la promoción académica y científica..." La crisis internacional y la guerra interna profundizaban aún más los antiguos problemas estructurales, y el mismo conflicto bélico tenía y sigue teniendo un origen estructural.

Los artículos del pasado quinquenio han venido ofreciendo análisis serios de los variados componenentes socio-económicos de esa realidad en crisis. Bastantes artículos eran resúmenes conden- 
sados de trabajos de graduación $\theta$ investigaciones realizadas en estos departamentos. Cada nuevo ano se abría con un análisis económico de los planes de emergencia o políticas de estabilización ejecutadas conforme a los vaivenes políticos o a los recetarios importados, indicando estos que generalmente no se lograba mejoría en las variables macroeconómicas, ni en las penalidades familiares del ciudadano común y corriente. Exponer esa realidad no siempre genera aplausos, sino mas bien suspicacias y malentendidos; pero parafraseando un dicho bien conocido se puede repetir que "La realidad os hará libres". El contenido de estos boletines servía de lectura y reflexión a nuestros estudiantes universitarios - tratando de hacer docencia aplicada a la realidad nacional- sirviendo de esta manera para generar esa "conciencia crítica y constructora de la realidad". Por ello nuestro Boletín ha tenido amplia acogida fuera del ámbito universitario y también nacional. Por desgracia es tan poco lo que se publica en el pais de parte de otras instituciones privadas y públicas, en forma de análisis equilibrado y académico, que la "realidad" queda desfigurada entre el "secretismo" y la "ingenuidad" de quienes la ocultan o falsifican.

El análisis de los problemas nos venía exigiendo dar un paso más: ¿Cómo salvar esta realidad? -EI "modelo económico"- dominante, interno y a la vez externo-dependiente, aunque se le afrada un aditivo de "social", ni enfrenta, ni presenta solución al más grave reto de la "satisfacción de las necesidades básicas".

El proyecto de investigación del Departamento de Economía ("Hacia la estabilización a través del desarrollo endógeno") se refleja en varios de los artículos recientes aparecidos en sucesivos números del boletín, y será el hilo conductor en el futuro cercano de la revista "REALIDAD". Es éste el objetivo y el salto cualitativo que pretendemos realizar como un deber universitario y en forma universitaria: conjugar los análisis del presente con una propuesta del futuro modelo económico-social.

Así comenzamos este primer número de nuestra publicación con tres investigaciones de esta Universidad. En la primera de ellas se estudia el proceso inflacionario de los últimos 15 afios, se verifican empíricamente varios modelos alternativos y se concluye que el comportamiento de los precios en una economía pequefia-abiertasubdesarrollada y dependiente como la salvadorefía se rige principalmente por el comportamiento de los costos relevantes. Gracias al detalle de la investigación y a la cuantificación del fenómeno analizado, se finaliza presentando algunas sugerencias para ser consideradas a la hora de formular políticas antiinflacionarias. 
El segundo trabajo constituye solamemte el apartado térico de una invesligación mucho más amplia actualmente en proceso, que busca explicar desde una perspectiva marxista la existencia de formas de producción no capitalistas en los paises del "submundo capitalista" como el nuestro, para ello se acude a la categoría subsunción indirecta del trabajo en el capilal.

En el trabajo final se analizan los principales movimientos campesinos en El Salvador, se argumenta que el elememo común en todos ellos ha sido la imposibilidad de reproducir la fuerza de trabajo y la vida social de estos sectores y que el elemento cualitativamente diferenciador ha sido el ideológico, el cual explica cada proceso y su desenlace. Sobre esta base, el autor deriva alguna conclusiones acerca de los límites y polencialidades de los alzamientos campesinos.

Iniciamos, pues, este tercer quinquenio de existencia con la alención puesta en las exigencias que se nos imponen para superar la crisis nacional. Como en el pasado, este esfuerzo quiere conlinuar siendo un diálogo técnico, democrático y constructivo y acogerá voluntariamente toda crítica y todo aporte académico para el mejor servicio de las mayorías populares de este país. 